\title{
Assessment of Biological Toxicity and Ecological Safety for Urban Black-Odor River Remediation
}

\author{
Rou-Rou Xu ${ }^{1,2}$, Zhou-Tao Pei ${ }^{1,2}$, Wen-Qian Wang ${ }^{1,2}$, Meng Zhang ${ }^{1,2}$, Li-Ling Zhang ${ }^{1,2}$, \\ Jing Zhang ${ }^{1,2}$, Wen-Qiang Wang ${ }^{1,2}$, Li-Wei Sun ${ }^{1,2, *}$ and Yi-Min Zhang ${ }^{3, *}$ \\ 1 School of Energy \& Environment, Southeast University, Nanjing 210096, China; \\ 220170522@seu.edu.cn (R.-R.X.); 220170623@seu.edu.cn (Z.-T.P.); 220160595@seu.edu.cn (W.-Q.W.); \\ 220180612@seu.edu.cn (M.Z.); 220180617@seu.edu.cn (L.-L.Z.); 213151155@seu.edu.cn (J.Z.); \\ 213152621@seu.edu.cn (W.-Q.W.) \\ 2 Taihu Lake Water Environment Engineering Research Center (Wuxi), Southeast University, \\ Wuxi 214061, China \\ 3 Research Center of Watershed Ecological Conservation and Water Pollution Control, Nanjing Institute of \\ Environmental Sciences, Ministry of Ecology and Environment of the People's Republic of China, \\ Nanjing 210042, China \\ * Correspondence: liwei-sun@seu.edu.cn (L.-W.S.); zym@nies.org (Y.-M.Z.); \\ Tel.: +86-150-7786-1046 (L.-W.S.); +86-189-5164-2953 (Y.-M.Z.)
}

Received: 6 January 2020; Accepted: 26 January 2020; Published: 6 February 2020

\begin{abstract}
The judgment and assessment of remediation effect on urban black-odor river still depend on the physical-chemical parameters and lack in ecological safety effects. A set of combined biological toxicity tests were applied to evaluate the ecological effects of one urban black-odor river before and after the remediation. The special growth rate of Chlorella vulgaris and mortality rate of Daphnia magna were used to assess acute toxicity. The Salmonella Typhimurium/Reverse Mutation Assay was applied to test the mutagenicity. The tests by C. vulgaris growth showed that there was no inhibition before and after remediation by overlying water, in contrast promoted the growth of $C$. vulgaris. The tests by $D$. magna showed slight toxicity on site $3 \#$ before remediation and nontoxic after remediation. The mutagenicity of organic extracts from overlying water at all sampling sites were positive before remediation, but were eliminated after remediation except from 3 of 4 sites on TA98 strain. The addition of the liver microsomal S9 induced the positive mutagenicity on site 4\# compared to S9 absence. The results clarified the applicable and the importance of the biological toxicity tests on assessing the remediation effect and potential ecological risk of urban black-odor river.
\end{abstract}

Keywords: urban black-odor river; overlying water; biological toxicity; mutagenicity

\section{Introduction}

Urban water refers to waters within the city that are closely related to urban functions, including rivers flowing through cities, river ditches, lakes, and other landscape water, which is an important part of urban ecosystems. Black-odor river is mainly caused by excessive discharge of pollutants by humans into water and the metabolism of algae and bacteria in waterbody [1].

At present, there is no definite assessment method or evaluation standard for black-odor river. The assessment methods in China are mainly divided into three categories: single index method, comprehensive index method, and other assessment methods.

Single indexes included physical indexes and chemical indexes. Physical indexes are mainly based on vision and smell to judge the degree of black-odor river. Generally, dissolved oxygen (DO) is taken as the main index to judge whether a river is black and odorous [2]. There are other basic water quality parameters for chemical indexes, such as chemical oxygen demand $\left(\mathrm{COD}_{\mathrm{Cr}}\right)$, biochemical 
oxygen demand $\left(\mathrm{BOD}_{5}\right)$, total nitrogen $(\mathrm{TN})$, total phosphorus (TP), ammonia nitrogen $\left(\mathrm{NH}_{4}{ }^{+}-\mathrm{N}\right)$, and redox potential (ORP).

The commonly used comprehensive indexes are black odor single factor index model [3], organic pollutant index model, and black odor multi-factor weighted index model [4]. In addition to the two assessment methods mentioned above, other model methods such as multivariate nonlinear regression model [5] and remote sensing monitoring and screening method [6] have also been gradually applied to the assessment of black-odor river. In fact, the comprehensive index methods and other assessment methods are based on the establishment of mathematical models, while the data for establishing these mathematical models are still physical and chemical indexes.

Due to the complex types of pollutants contained in black-odor river, including not only toxic and harmful inorganic substances, nitrogen and phosphorus, but also a wide variety of persistent organic pollutants that are difficult to degrade. If only sensory physical indexes and water quality chemical parameters are used to evaluate the remediation effect of black-odor river, the result is obviously lack of ecological safety judgment and do not know whether the remediation process will actually reduce the toxic effects of black-odor river on aquatic organisms. Therefore, there is an urgent need for biological methods that can assess the toxicity and ecological safety of urban black-odor river before and after remediation.

For the evaluation of water toxicity, biological toxicity tests have been proved to be valuable tools for detecting the total biological potential risk of a mixture of pollutants [7]. The Whole Effluent Toxicity Test (WET) proposed by the United States Environment Protection Agency (USEPA) recommends using multiple test species [8], the standardized plants from fresh water and invertebrates, to evaluate the comprehensive toxicity of effluents. Fang et al. [9] found that green algae and crustacean was sensitive to the effluents from electronic and electroplate factories, and they also found that organic pollutants were the main contributing factor to the toxicity of effluents from these factories.

At present, few studies have applied biological toxicity to the evaluation of black-odor river. It is speculated that the biological toxicity tests could be used to evaluate the ecological safety and remediation effect for those black-odor rivers. The present study supposed the water from the black-odor river to be a whole effluent, then their toxic effects to the aquatic system were evaluated, and the reduce of the toxic effects after the remediation were also accessed.

Salmonella Typhimurium/Reverse Mutation Assay (Ames test) was designed to detect chemically induced mutagenesis. It can specially detect the mutagenicity of mixed pollutants quickly and accurately $[10,11]$. So far, it has been widely used to evaluate the mutagenicity of complex mixtures in drinking waters and polluted rivers. Park et al. [12] found that the organic extracts from the drinking tap water in Seoul, Taejon, and Suwon were mutagenic on TA98 without S9 mix and on TA100 with and without S9 mix. Kutlu et al. [13] reported that the presence of mutagens caused frameshift and base-pair substitution mutations in water and sediments of the Porsuk River by Ames test. The previous studies supported that the Ames test can be applied in assessing the mutagenicity of organic extracts from black-odor river.

In this study, a set of combined tests including acute toxicity tests and Ames tests were employed to assess the comprehensive impact of pollutants from Shengtongbang river on aquatic ecological system before and after the remediation. The acute toxicity was performed with Chlorella vulgaris and Daphnia magna. The mutagenicity assessment of the organic extracts of the water was performed by Ames test. The results are expected to assess the toxicity changes before and after remediation and ecological safety for black-odor river, and further to improve the remediation process based on the biological toxicity results. 


\section{Materials and Methods}

\subsection{Sampling Sites and Remediation Process}

The urban black-odor river in this study was located in Shentongbang, Luoyang town, Wujin district, Changzhou city, China. According to the preliminary investigation, there were three natural villages and 64 factories along the Shentongbang river. As a result of the weak environmental awareness among local residents and manufacturers, the direct discharge of domestic and industrial sewage, improper diversion of rain and sewage, and the existence of leakage years ago had caused the deterioration of water quality even if there existed wastewater treatment plants. Although the regulation of sewage discharge has been strengthened and there was no existence of illegal discharge of sewage after remediation, however, contaminants discharged before are still being deposited in the sediments and can be released to the waterbody, causing harm to aquatic life. A lot of black clumps with fetid odor can be seen floating on the river. It was suggested that there might exist organic pollution, while the concentrations of heavy metals $(\mathrm{Cr}, \mathrm{Cu}, \mathrm{Mn}, \mathrm{Pb}, \mathrm{Zn})$ detected by inductively coupled plasma-mass spectrometry (ICP-MS) did not exceed Chinese national standard [14]: Environmental Quality Standards for Surface Water (GB3838-2002) for class II.

Shentongbang river was thoroughly applied by several remediation measures. First, through the optimized control of the sluice, a certain exchange of water can be carried out between Wujin Port and Shentongbang river, thereby improving the water quality. Then, the discharge of the factory's legacy sewage outlets was found out and strictly prohibited, the decentralized domestic sewage was centralized and treated, ecological floating beds and immobilized microorganisms were applied to block flow, settle, and intercept pollutants entering the river. Finally, sediment ecological slope protection technology and planting of aquatic plant at vertical barge vertical were also carried out.

Four sampling sites (3\#, 4\#, 5\#, 7\#) on Shentongbang were chosen to evaluate the biological toxicity of overlying water before and after remediation (Figure 1). Overlying water is the supernatant in river, which also called covering water [8]. Site $3 \#$ (N 31 $40^{\prime} 23^{\prime \prime}$, E $\left.120^{\circ} 4^{\prime} 2^{\prime \prime}\right)$ was beside Guolian whiteboard factory with four discharge outlets directly to the river. Site $4 \#\left(\mathrm{~N} 31^{\circ} 40^{\prime} 15^{\prime \prime}, \mathrm{E} 120^{\circ} 4^{\prime} 0^{\prime \prime}\right)$ was under a bridge near Yaokang oil company. There were five discharge outlets along the river. Site $5 \#$ (N $31^{\circ} 40^{\prime} 12^{\prime \prime}, \mathrm{E} 120^{\circ} 3^{\prime} 59^{\prime \prime}$ ) was in Sanlian cloth industry Co., Ltd., where the tributaries flowed into the main stream. Site $7 \#\left(\mathrm{~N} 31^{\circ} 40^{\prime} 8^{\prime \prime}, \mathrm{E} 120^{\circ} 3^{\prime} 59^{\prime \prime}\right)$ was next to Yuanyue cold storage plant where three discharge outlets were along the river.

The water samples were collected over a $24 \mathrm{~h}$ period according to standard sampling methods [15]. The environmental parameters on sampling site, such as temperature, $\mathrm{pH}$ and dissolved oxygen (DO) were measured. The water samples were sealed, then transported to the laboratory as soon as possible. The airtight water bottles were stored in dark at $-20^{\circ} \mathrm{C}$ for the toxicity tests.

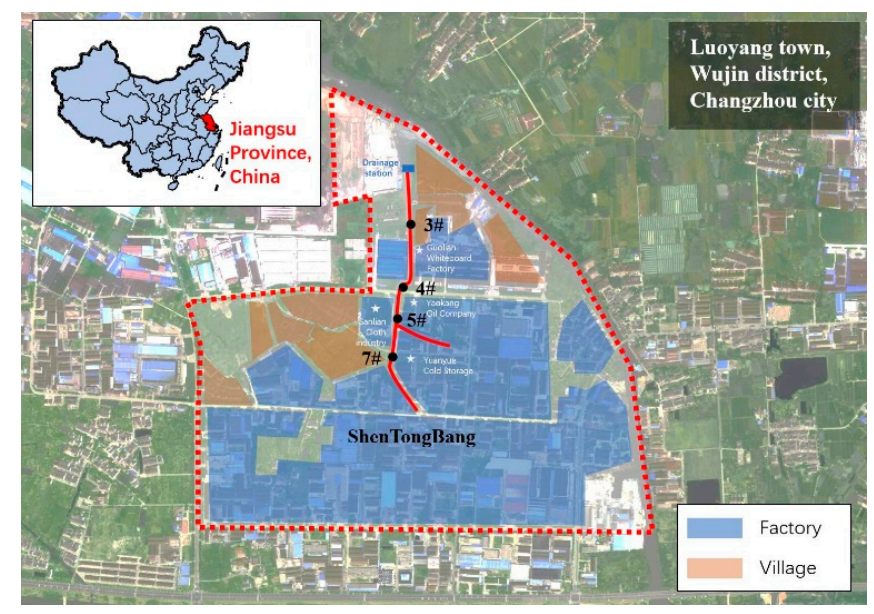

Figure 1. Sampling sites of overlying water in Shentongbang. 


\subsection{Physicochemical Analysis of Water Quality}

The overlying water was filtered with $0.45 \mu \mathrm{m}$ filter paper. Chemical oxygen demand (COD), ammoniac nitrogen $\left(\mathrm{NH}_{4}{ }^{+}-\mathrm{N}\right)$, total nitrogen (TN), and total phosphorus (TP) were analyzed according to standard methods for the examination of water [16].

\subsection{Toxicity Tests}

\subsubsection{Acute Toxicity Experiments with C. vulgaris}

C. vulgaris (FACHB-8) was obtained from the Freshwater Algae Culture Collection of the Institute of Hydrobiology, Chinese Academy of Sciences (Wuhan, China). The algae were cultured for three generations in the laboratory before the toxicity experiments. Algal cells in the logarithmic growth phase were used for toxicity experiments, which were conducted in an illumination incubator to maintain the same condition: light: $4000-6000 \mathrm{~lx}$, temperature: $23 \pm 2{ }^{\circ} \mathrm{C}, \mathrm{pH}: 7.1$.

Ninety-six hours of acute tests by $C$. vulgaris were conducted according to Chinese national standard [17]: Chemicals-Alga Growth Inhibition Test (GB/T21805-2008). The dilution water was used to make a series of concentrations of the overlying water for the experiments. The dilution water had the same hardness and alkalinity as the overlying water, which was prepared according to USEPA 2002. The initial concentration of algae in the solution was $510^{4}$ cells $/ \mathrm{mL}$. Three parallel lines were set for each group, including a blank control group (BG11 medium, NC) for analysis. The correlation between algal density and absorbance at $680 \mathrm{~nm}$ were plotted before the experiment. During the test period, the absorbance was measured every $24 \mathrm{~h}$, and the density of algae was calculated based on the density-absorbance curve. The test lasted for $96 \mathrm{~h}$.

The specific growth rate $\mu$ was calculated as:

$$
\mu=\frac{\ln x_{f}-\ln x_{0}}{t_{f}-t_{0}}
$$

where $t_{0}$ is the beginning time of the test, $t_{f}$ is the ending time, and $x_{0}$ is the density of algae at the beginning, $x_{f}$ is the density of algae at the ending.

A toxic unit (TU) approach was employed to calculate the mixed toxicity of all toxicants in an effluent, which were calculated based on the formulas below [18]:

$$
T U=\frac{100 \%}{L C_{50}\left(E C_{50}\right)}
$$

where $L C_{50}$ or $E C_{50}$ is the dilution or concentration of water samples when half of the aquatic organisms are dead or showed growth inhibition.

The acute toxicity results were classified according to the following toxicity classification system [19], as shown in Table 1:

Table 1. Toxicity classification system.

\begin{tabular}{ccc}
\hline TU & Classification & Toxicity \\
\hline $\mathrm{TU}<0.4$ & I & no acute toxicity (NT) \\
$0.4 \leq \mathrm{TU}<1$ & II & slight acute toxicity (ST) \\
$1 \leq \mathrm{TU}<10$ & III & acute toxicity (AT) \\
$10 \leq \mathrm{TU}<100$ & $\mathrm{IV}$ & high acute toxicity (HT) \\
$\mathrm{TU} \geq 100$ & $\mathrm{~V}$ & very high acute toxicity (VT) \\
\hline
\end{tabular}




\subsubsection{Acute Toxicity Experiments with D. magna}

D. magna was obtained from the Institute of Hydrobiology, Chinese Academy of Sciences. They are cultured in the laboratory, and tested for sensitivity to potassium dichromate before the toxicity experiments. D. magna at 6-24 h old were employed in the toxicity test. The experiments were conducted using an illumination incubator to maintain the same conditions: $19 \pm 1{ }^{\circ} \mathrm{C}, \mathrm{DO} \geq 2 \mathrm{mg} / \mathrm{L}$, pH 7.0-8.0, and a 16:8 light: dark cycle with light intensity $<1000 \mathrm{~lx}$.

Forty-eight hours of acute tests by D. magna were conducted according to Chinese national standards [20]: Method for Acute Toxicity Test of Daphnia Magna Straus (GB/T 16125-2012). Before the experiments, the sensitivity of $D$. magna was tested with potassium dichromate and the results met the quality control requirements for D. magna acute toxicity tests. In formal experiments, a series of concentrations of 40-mL experimental solutions (overlying water diluted by percentage with aerated dilution water) were prepared in a 100-mL glass beaker. Four concentration groups were set for each point, including the solvent control group (aerated dilution water, NC). Three parallel lines were set for each group and ten $D$. magna were added to each glass beaker. The numbers of dead D. magna were recorded every $24 \mathrm{~h}$, and the mortality rates were calculated. The test was lasted for $48 \mathrm{~h}$.

The mortality rate I was calculated as:

$$
I=\frac{N}{N_{0}} \times 100 \%
$$

where $N_{0}$ is the number of D. magna at the beginning, $N$ is the number of dead D. magna after $48 \mathrm{~h}$.

The toxic unit (TU) and classification criteria for acute toxicity $(48 \mathrm{~h})$ with $D$. magna was the same as C. vulgaris.

If the mortality in a $100 \%$ effluent concentration was between $10 \%$ and $49 \%$, the TUs were derived as follows:

$$
T U=0.02 \times \text { mortality }(\%)
$$

A toxic unit of zero was allocated to mortalities between $0 \%$ and $10 \%$ in $100 \%$ effluent exposure [21].

\subsubsection{Ames Test}

The mutagenicity of overlying water organics was tested by Ames test. The organic chemicals in the overlying water were extracted by a solid-phase extraction method. Oasis HLB sorbent has been reported with good retention for both polar and non-polar compounds (Liu et al.). This kind of sorbent allow efficient extraction of different pesticides or environmental contaminants such as 2,4-Dichlorophenoxyacetic acid (2,4-D), trichlorophenol (TCP), polycyclic aromatic hydrocarbons (PAHs), herbicides (i.e., atrazine), etc. Waters Oasis HLB cartridges (6 cc, $200 \mathrm{mg}$ sorbents) were conditioned using $10 \mathrm{~mL}$ methanol, followed by $10 \mathrm{~mL}$ Milli-Q water. Then, $1 \mathrm{~L}$ of each water samples was passed through the HLB cartridge at a speed of $3-5 \mathrm{~mL} / \mathrm{min}$. After the samples were loaded, $10 \mathrm{~mL}$ of Milli-Q water was used to wash each cartridge. The HLB cartridges were then eluted by $10 \mathrm{~mL}$ hexane/acetone (1:1 by volume), $10 \mathrm{~mL}$ dichloromethane and $10 \mathrm{~mL}$ methanol in sequence. The three eluates were combined and dried under a gentle nitrogen stream, and the final extract was reconstituted in $1 \mathrm{~mL}$ dimethyl sulfoxide (DMSO) for the next mutagenicity experiment.

Four S. Typhimurium strains, TA97, TA98, TA100, TA102 were employed in Ames test. The first two strains primarily detect the genotoxic substance of frameshift mutants and the other two strains detect DNA as a mutagenic substance for base pair substitution. The strains were provided by Jiangsu Provincial Center for Disease Control and Prevention and Guizhou Medical University. Rat liver microsomal (S9) was purchased from CHI Scientific, Inc., (Jiangsu, China). Biological characterization, preservation, mutagenesis procedures of these four S. Typhimurium strains were with reference to Chinese standards [22]: Safety and Technical Standards for Cosmetics (2015). The positive control experiments were conducted to demonstrate the sensitivity of the strains. 
The mutagenicity ratio (MR) was used to determine the genetic toxicity of the water samples, which was calculated as:

$$
M R=\frac{X}{X_{0}}
$$

where $X$ is the number of surviving colonies on organic extract-treated plates and $X_{0}$ is the number of the negative control group (NC).

When the mutagenicity ratio $(\mathrm{MR}) \geq 2$, with the dose-response relationship and the background was normal, the mutagenesis is judged as positive.

\subsection{Statistical Analysis}

Origin Pro 9 software (Origin Lab, Northampton, MA, USA) was applied for data processing. IBM SPSS version 20 software (IBM Corp, Armonk, NY, USA) was applied for the calculation of 96-h $\mathrm{EC}_{50}$ and $48-\mathrm{h} \mathrm{LC}_{50}$ value with their $95 \%$ confidence intervals. The results of Ames tested for overlying water organic were expressed as the Mean \pm SD.

Statistical significance was evaluated with one-way analysis of variance (ANOVA) followed by Dunnett's multiple comparison tests (comparison between NC and water samples, $p<0.05$ or $p<0.01$ ).

\section{Results and Discussion}

\subsection{Water Quality}

The water quality of the overlying water before and after remediation are shown in Table 2. The results indicated that before remediation, $\mathrm{COD}, \mathrm{TN}, \mathrm{TP}, \mathrm{NH}_{4}{ }^{+}-\mathrm{N}$, and $\mathrm{DO}$ exceeded the environmental quality standards for surface water (GB3838-2002) seriously. The black-odor river was classified as substandard V water body. After remediation, the COD from all sites was reduced from 49.66-91.80 mg/L to less than $50 \mathrm{mg} / \mathrm{L}$, the $\mathrm{TN}, \mathrm{TP}$, and $\mathrm{NH}_{4}{ }^{+}-\mathrm{N}$ were also removed effectively after remediation. DO was obviously improved due to the remediation, with all sites meeting the IV even II standard (GB3838-2002) except for site 7\#. However, the TN and TP of most sites were still higher than $\mathrm{V}$ standard. Only TP from 3\# met the index of case-V water. And all parameters of water from $7 \#$ were exceeded $\mathrm{V}$ standard except $\mathrm{pH}$.

Generally speaking, the water quality was improved significantly by the remediation, but there were still two problems. The first was that the TN and TP from the water were higher than the $\mathrm{V}$ standard after the remediation. It was believed that the water eutrophication was serious. The second was that the water from site $7 \#$ after the remediation still belonged to substandard V water body, indicated that the pollution caused by the cold storage plant was serious.

Table 2. Physicochemical parameters of the overlying water before and after remediation.

\begin{tabular}{|c|c|c|c|c|c|c|c|}
\hline \multicolumn{2}{|c|}{$\begin{array}{l}\text { Parameters } \\
(\mathrm{mg} / \mathrm{L})\end{array}$} & \multirow{2}{*}{$\begin{array}{c}\text { COD } \\
55.68^{*}\end{array}$} & \multirow{2}{*}{$\frac{\text { TN }}{13.05^{*}}$} & \multirow{2}{*}{$\begin{array}{c}\text { TP } \\
0.723^{*}\end{array}$} & \multirow{2}{*}{$\frac{\mathrm{NH}_{4}^{+}-\mathbf{N}}{5.007^{*}}$} & \multirow{2}{*}{$\begin{array}{l}\text { DO } \\
0.58\end{array}$} & \multirow{2}{*}{$\begin{array}{c}\begin{array}{c}\mathrm{pH} \\
\text { (Non-Dimensional) }\end{array} \\
7.32\end{array}$} \\
\hline \multirow{4}{*}{$\begin{array}{c}\text { Before } \\
\text { remediation }\end{array}$} & $3 \#$ & & & & & & \\
\hline & $4 \#$ & $54.18^{*}$ & $13.97^{*}$ & $0.832 *$ & $6.085 *$ & 0.49 & 7.51 \\
\hline & $5 \#$ & $49.66^{*}$ & 11.51 * & 0.604 * & $7.533 *$ & 0.63 & 7.46 \\
\hline & 7\# & $91.80 *$ & $15.85^{*}$ & $1.624^{*}$ & $9.694 *$ & 0.77 & 7.29 \\
\hline \multirow{4}{*}{$\begin{array}{c}\text { After } \\
\text { remediation }\end{array}$} & $3 \#$ & 34.55 & 9.55 * & 0.355 & 1.908 & 6.970 & 7.71 \\
\hline & $4 \#$ & 28.73 & 10.15 * & $0.406^{*}$ & 1.426 & 3.570 & 7.94 \\
\hline & $5 \#$ & 36.15 & $9.89 *$ & $0.447^{*}$ & 1.828 & 4.940 & 8.12 \\
\hline & 7\# & 46.64 * & 14.41 * & 1.071 * & 2.015 * & 1.64 * & 8.17 \\
\hline
\end{tabular}

* Exceed the China's water-quality standard for class V (GB3838-2002). 


\subsection{Acute Toxicity of Overlying Water before and after Remediation}

\subsubsection{Acute Toxicity on C. vulgaris}

Table 3 is the result of 96-h specific growth rate of $C$. vulgaris for overlying water before and after remediation. After $96 \mathrm{~h}$, the specific growth rates of $C$. vulgaris in overlying water from all sites were higher than that of the control group no matter remediation or not. The result indicated that the overlying water promoted the growth of $C$. vulgaris. According to the water quality measurement results, it is speculated that the excessive TN and TP in water provided excessive nutrients for $C$. vulgaris, so the growth rate in overlying waters were higher than the control group. The promotion effect was ranked from large to small respectively: $4 \#, 3 \#, 5 \#, 7 \#$, which was consistent with the water quality results (Table 1). Site $4 \#$ showed highest promotion effects, since it was least polluted according to water quality analysis, while site $7 \#$ showed lowest promotion because of its worst water quality.

The result indicated there was no inhibitory effect on $C$. vulgaris by overlying water, whatever before or after the remediation. It was believed that the promotion effect by water eutrophication exceeded that of water toxicity on C. vulgaris. The results suggested the advantage of biological toxicity tests, which can not only test the overall toxicity of all pollutants contained in waters, but also test the effect of the nutrient elements from waters by the growth rate of algae. The results indicated that the restrictions on the TN and TP are still needed in the future.

Table 3. Specific growth rate (96-h) of C. vulgaris to overlying water before and after remediation.

\begin{tabular}{ccc}
\hline Time & Before Remediation & After Remediation \\
\hline Sites & \multicolumn{1}{c}{ Specific Growth Rate $\mathbf{( 9 6}$ h) } \\
\hline $3 \#$ & $89.11 \% \pm 6.95 \% *$ & $91.04 \% \pm 4.44 \%$ \\
$4 \#$ & $93.80 \% \pm 1.34 \% * *$ & $94.01 \% \pm 2.36 \% *$ \\
$5 \#$ & $88.55 \% \pm 2.69 \%$ & $92.62 \% \pm 3.71 \% *$ \\
$7 \#$ & $86.32 \% \pm 0.73 \%$ & $88.47 \% \pm 5.82 \%$ \\
NC & $81.47 \% \pm 1.85 \%$ & $85.27 \% \pm 1.44 \%$ \\
\hline
\end{tabular}

Comparison between NC (BG11) and water samples: *. $p<0.05,{ }^{* *} p<0.01$.

\subsubsection{Acute Toxicity on D. magna}

Table 4 is the 48 -h $\mathrm{LC}_{50}$ on $D$. magna by overlying waters. When the proportion of raw water in all spots was $100 \%$, the mortality rate of D. magna did not exceed $50 \%$, which could calculate the TU and evaluate toxicity according to Equations (2) and (4).

According to the toxicity classification system [19], the toxicity of the overlying water to D. magna from $3 \#$ was slightly toxic before the remediation of the river. The other sites were non-toxic. The comprehensive toxicity of the overlying water to $D$. magna varied from strong to weak from sites 3\#, 7\#, 5\#, and 4\#. After the remediation, the overlying water of all sites showed no toxic effect on D. magna, especially for site 4\#, there was no death of D. magna caused by overlying water.

From the results, the TUs of most spots decreased after remediation compared to those before remediation, proved that the toxicity of the overlying water decreased by the remediation measures, especially, the TU of site $4 \#$ after remediation was 0 , lower than other spots. These toxicity results are all consistent with the improvement of water quality (Table 2), suggesting the remediation on the urban black-odor river is effective. Before the remediation on site 3\#, the overlying water had light lethal effect on D. magna, it could be related to the contaminants discharged from the whiteboard factory. It is known that the production of whiteboard is inseparable from plastics, and the waste water discharged from the whiteboard factory may contain microplastics and plasticizers that are difficult to degrade. Studies have shown that microplastics can be ingested by zooplankton in the environment and affect the growth and feeding ability of the organism [23].

Moreover, the toxicity result is inconsistent with the results of $C$. vulgaris. From the results above, the TN and TP in the overlying water exceeded the China's water-quality standard (GB3838-2002). 
In fact, the effects of these two elements on C. vulgaris and D. magna were different. In principle, $\mathrm{N}$ and $\mathrm{P}$ are necessary nutrients for algae $C$. vulgaris, which will promote the growth of $C$. vulgaris, while the excessive TN and TP may have certain toxic effects on D. magna. The result not only reflected the changes before and after remediation but also the different effects on different species of aquatic organisms.

Table 4. Biological toxicity assessment on overlying water by D. magna before and after remediation.

\begin{tabular}{ccccccccc}
\hline \multirow{2}{*}{ Sites } & \multicolumn{2}{c}{ 3\# } & \multicolumn{2}{c}{ 4\# } & \multicolumn{2}{c}{$5 \#$} & \multicolumn{2}{c}{ 7\# } \\
\cline { 2 - 9 } & Before & After & Before & After & Before & After & Before & After \\
\hline $48-\mathrm{h}$ & $218.67 \%$ & $299.94 \%$ & $629.80 \%$ & $/$ & $519.70 \%$ & $500 \%$ & $311.64 \%$ & $1515.15 \%$ \\
LC $_{50}$ a & 0.46 & 0.33 & 0.16 & 0 & 0.19 & 0.20 & 0.32 & 0.07 \\
TU & ST & NT & NT & NT & NT & NT & NT & NT \\
Toxicity & a & &
\end{tabular}

\subsection{Mutagenicity of Overlying Water}

\subsubsection{Ames Test of Overlying Water Extracts Before and After Remediation}

Table 5 is the reverse mutation colonies of four S. Typhimurium strains detected by organic extracts of overlying water from four sites by Ames tests. The number of reverse mutation colonies in blank and DMSO controls are in the reasonable numbers, which are proposed in the Ames bacterial mutagenicity assay [22], proving that the dissolution of organics by DMSO would not add any mutagenicity to the extraction. The MR values at every site before and after remediation are compared in Figure 2.

On site 3\# (in Figure 2a), before remediation, MRs of TA98 and TA100 were slightly higher than 2, indicated the mutagenicity of organic extracts from overlying water. After remediation, the TA98 strain still showed weak positive, while there was no mutagenicity detected by other strains. The MRs of TA97, TA100 and TA102 strains decreased by the remediation, implying the remediation was effective. Notably, for TA98 strain, the MR of after remediation was slightly higher than that of before, showing the possible conversion of organics in water.

As for the toxicity type of site 3\#, it may be related to the plasticizers in wastewater from the whiteboard factory. The plasticizers are essential additives in the production of plastic whiteboards. The plasticizers such as phthalate chemicals [24] and bisphenol A [25] have been proved mutagenic by Ames test and other microbial experiments, which may contribute to the mutagenicity of water near whiteboard factory. As for the increase of MRs of TA98 strain, it could result from the release of organics absorbed in sediments because organics with hydrophobic nature and weak degradation characteristics had accumulate in sediments [26]. After the equilibrium between sorbed and aqueous phases was broken, the absorbed organics could repartition into water and cause secondary pollution to the surroundings $[27,28]$.

On site 4\# (Figure 2b), before remediation, the MR of TA98 strain was much higher than 2, exhibited a significant mutagenicity, but there was no mutagenicity detected by other strains. After remediation, the TA98 strain still showed weak positive result, but declined obviously $(p<0.01)$. The other strains showed negative results before remediation, and also the MRs of TA100 and TA102 strains dropped a little after remediation. These results all implied that the remediation of black-odor river reduced the mutagenicity of overlying water.

As for the toxicity type of site $4 \#$, this could be resulted from the vegetable oil company. The vegetable oil wastewater belongs to organic wastewater, which contains mainly oil-organic matter, a small amount of protein colloids, pigments, inorganic salts and trace amounts of alkanes, cycloalkane, olefins, and aromatic (PAH) compounds. These organics are difficult to degrade in natural waters in a short time, thus may contribute to the mutagenicity of overlying water. 
On site 5\# (Figure 2c), before remediation, the MRs of TA98, TA100, and TA102 strains were all higher than 2, showing the mutagenicity from the overlying water to the three strains. For TA97 strain, the number of reverse mutation colonies before remediation was lower than that in the blank group (Table 5). It may be an DNA or cell level damage which inhibited the growth of the strain. After remediation, the number of reverse mutation colonies of TA97 strain returned to normal, and the mutagenicity results still showed negative. Although the mutagenicity on TA98 strain still showed weak positive after remediation, the MR of TA98 decreased significantly $(p<0.01)$, and the MRs of TA100 and TA102 strains also decreased, suggesting the decline of mutagenicity of overlying water by the remediation.

The results from site $5 \#$ suggested the complexity of organics in the overlying water. Site $5 \#$ is near a cloth factory, the wastewater of the factory is complex and diverse, which cannot be completely removed by the traditional sewage treatment process. The wastewater generally contains additives, detergents, surfactants, and dyes, which are carcinogenic, teratogenic, and mutagenic [29]. These could also contribute to the diversity of mutagenicity results on site $5 \#$.

On site 7\# (Figure 2d) before remediation, the overlying water showed strong mutagenicity to strains TA98 and weak mutagenicity to strains TA100, the mutation types were similar to site 5\#. After remediation, the MRs of four strains were all less than 2, indicating that the mutagenicity of overlying water at site 7\# disappeared by remediation. The TA97 and TA102 strains were inhibited before remediation.

The mutagenicity results on site $7 \#$ before remediation may resulted from the organic wastewater from the cold storage plant, since the main organic pollutants in the cold storage plant were petroleum, benzene, etc., and these organic substances all had certain genotoxicity [30,31]. It was speculated that the cold storage plant may discharge these organics into the river before remediation.

From the results, the organics could be possible mutagenicity contaminants at these sites in addition to TN and TP. The Oasis HLB sorbent has been reported with efficient extraction of different pesticides or environmental contaminants, and its recoveries and detection limits in surface waters were 80\%-108\% and 1-15 ng/L respectively by HLB solid-phase extraction and gas-chromatography/mass spectrometry [32]. It is believed that most of the organics can be extracted from the black-odor river.

In general, positive mutagenicity results were detected from the overlying water of all the sites on TA98, TA100, and TA102 strains before remediation, indicated the diverse mutagenicity types, including the frameshift mutants and base pair substitution. Except the weak mutagenicity of TA98 strain, no mutation was detected from all sites on other strains after remediation. The mutagenicity of organics from the overlying water decreased after remediation, which is consistent with the improvement of water quality and the acute toxicity results of D. magna.

Although the acute toxicity of overlying water by D. magna showed no toxicity of overlying water of site 4, 5, 7 before remediation, however the Ames test indicated the mutagenicity from the organic extracts from these sites, it is proved that there is still an genetic toxicity risk existing in the waterbodies. So the mutagenicity assays can be considered as an effective tools for environmental monitoring and choosing appropriate treatment processes, such as active carbon or advanced oxidation processes [33]. In other words, the ecological restoration of black-odor river still needs to be improved to eliminate this kind of mutagenicity. 
Table 5. Reverse mutation colonies of four strains detected by overlying water extracts before and after remediation.

\begin{tabular}{|c|c|c|c|c|c|c|c|c|}
\hline \multirow{2}{*}{ Samples } & \multicolumn{2}{|c|}{ TA97 } & \multicolumn{2}{|c|}{ TA98 } & \multicolumn{2}{|c|}{ TA100 } & \multicolumn{2}{|c|}{ TA102 } \\
\hline & Before & After & Before & After & Before & After & Before & After \\
\hline $3 \#$ & $373 \pm 31.5$ & $189 \pm 7.0$ & $88 \pm 2.8^{*}$ & $104 \pm 4.9 *$ & $419 \pm 35.4^{*}$ & $125 \pm 7.8$ & $365 \pm 6.4$ & $287 \pm 23.4$ \\
\hline $4 \#$ & $160 \pm 15.7$ & $165 \pm 4.9$ & $497 \pm 24.0$ * & $94 \pm 1.4^{*}$ & $286 \pm 14.1$ & $139 \pm 5.7$ & $340 \pm 20.7$ & $277 \pm 23.3$ \\
\hline $5 \#$ & $79 \pm 5.7^{\mathrm{a}}$ & $190 \pm 11.1$ & $421 \pm 33.1 *$ & $112 \pm 4.6^{*}$ & $412 \pm 26.9 *$ & $162 \pm 11.0$ & $979 \pm 31.1^{*}$ & $380 \pm 33.9$ \\
\hline 7\# & $0^{a}$ & $201 \pm 11.3$ & $608 \pm 35.4^{*}$ & $84 \pm 7.0$ & $538 \pm 45.2 *$ & $149 \pm 12.7$ & $90 \pm 6.8^{a}$ & $316 \pm 8.5$ \\
\hline Blank & \multicolumn{2}{|c|}{$185 \pm 10.6$} & \multicolumn{2}{|c|}{$45 \pm 2.1$} & \multicolumn{2}{|c|}{$181 \pm 4.4$} & \multicolumn{2}{|c|}{$328 \pm 10.6$} \\
\hline DMSO & \multicolumn{2}{|c|}{$191 \pm 10.8$} & \multicolumn{2}{|c|}{$43 \pm 3.5$} & \multicolumn{2}{|c|}{$196 \pm 11.1$} & \multicolumn{2}{|c|}{$291 \pm 1.4$} \\
\hline
\end{tabular}

a bacterial inhibition effect; ${ }^{*} \mathrm{MR} \geq 2$ compared to control.

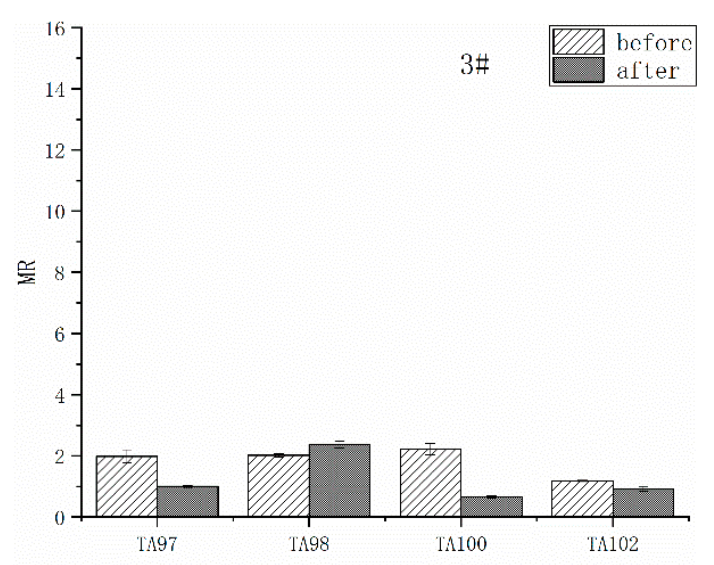

(a)

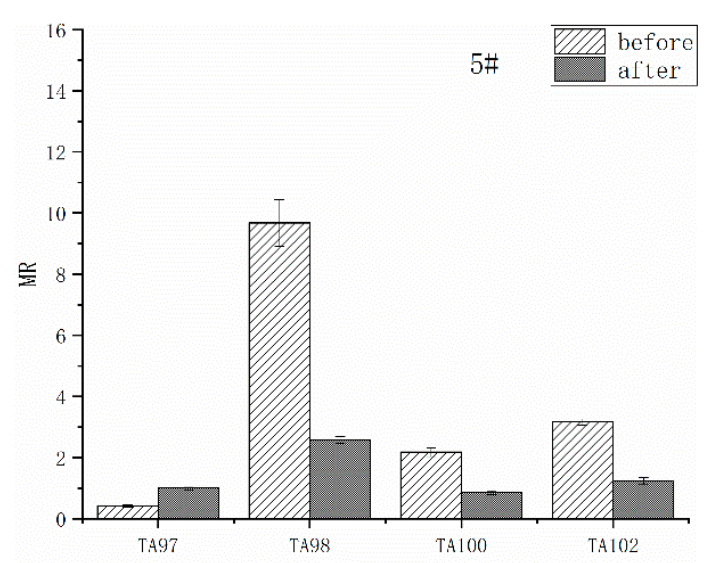

(c)

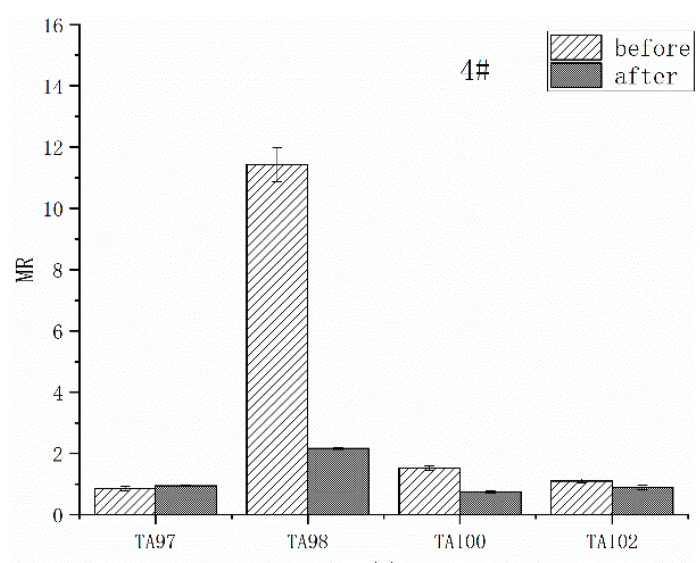

(b)

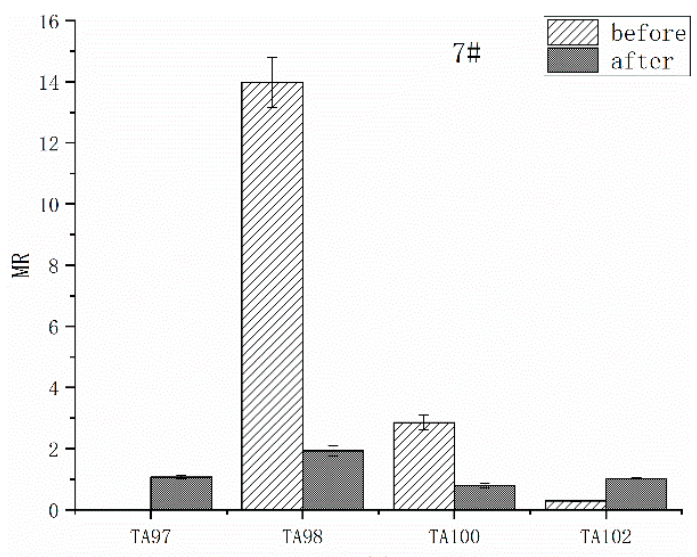

(d)

Figure 2. Mutagenesis of four strains by overlying water before and after remediation in the absence of liver microsomal S9; (a) site 3\#; (b) site 4\#; (c) site 5\#; (d) site 7\#. The mutagenicity ratio (MR) is the average ratio from 3 independent experiments.

3.3.2. Ames Test of Overlying Water after Remediation in the Presence and Absence of Liver Microsomal S9

To verify whether the toxicity of mutagenic contaminants in the overlying water will be changed by the metabolism of the microorganisms, the liver microsomal S9 were introduced to the Ames tests, for those water samples with negative mutations after remediation.

Table 6 is the reverse mutation colonies of four S. Typhimurium strains detected by overlying water organic extracts after remediation. The MR values in the presence (+S9) and absence (-S9) of S9 at four sites are compared in Figure 3. For TA97 strain, the mutation colonies in DMSO were a little higher 
than that of blank control. However, there was no significant mutagenicity detected from DMSO group, proved that the dissolution of organics by DMSO would not add any mutagenicity to the extraction.

On site 3\# (Figure 3a), the MR values of four strains were all less than 2, both with and without S9, indicating that the overlying water after remediation had no mutagenicity to four strains. Additionally, the MRs of TA100 and TA102 strain raised slightly when added S9.

On site 4\# (Figure 3b), in the presence of S9, the MRs of TA100 and TA102 strain raised. In particular, the MR of TA100 strain was over 2 and 3 times compared to that in the absence of S9. The result indicated that the mutagenicity of organics was increased after metabolism.

For site 5\# and 7\# (Figure 3c,d, respectively), the results were similar to that on site 3\#. There was no mutagenicity detected for four S. Typhimurium strains both in the presence and absence of S9. And the change of MRs of four strains was also as same as that on site 3\#.

From the results above, the addition of $S 9$ metabolized organics in overlying water, increasing the mutagenicity (site $4 \#$ to TA100). The fact revealed that the organic chemicals present in the overlying water will be changed by the metabolism of microorganism and therefore cause potential risk to aquatic ecosystem. Furthermore, the process of the bio-concentration, bio-accumulation, and bio-amplification in the natural ecosystem may also be a threat to the aquatic life. Thus, there is a need for more stringent monitoring of such ecological risk to predict or prevent the damage to the ecosystem in the future.

In acute toxicity tests by C. vulgaris and D. magna and Ames tests by four S. Typhimurium strains, the different level toxic tests were employed in the present study to reveal the different effects of toxicants from the overlying water.

In conclusion, the overlying water was not highly toxic to C. vulgaris and D. magna, but had certain mutagenicity to four S. typhimurium strains, especially for the TA98 and TA100 strains which could cause frameshift and base-pair substitution mutations. Although the mutagenicity was detected from the organic extract of the overlying water, it confirmed that there did exist some mutagenic contaminants in the overlying water, even after remediation. It could be predicted that the contaminants with no mutagenicity in the environment could be changed by the microbial metabolism. So, the assessment of remediation effect for black-odor river should be monitored in a long time to observe the possible ecological risk. The comprehensive assessment of the impact of the black-odor river through multiple levels toxicity tests would provide a scientific method for assessing the safety of natural ecosystem in the future.

Table 6. Reverse mutation colonies of four strains detected by overlying water after remediation in the presence and absence of liver microsomal S9.

\begin{tabular}{|c|c|c|c|c|c|c|c|c|}
\hline \multirow{2}{*}{ Samples } & \multicolumn{2}{|c|}{ TA97 } & \multicolumn{2}{|c|}{ TA98 } & \multicolumn{2}{|c|}{ TA100 } & \multicolumn{2}{|c|}{ TA102 } \\
\hline & $-\mathrm{S} 9$ & +S9 & $-\mathrm{S} 9$ & +S9 & $-\mathrm{S} 9$ & +S9 & $-\mathrm{S} 9$ & +S9 \\
\hline $3 \#$ & $255 \pm 9.2$ & $159 \pm 14.7$ & $51 \pm 3.5$ & $42 \pm 2.8$ & $125 \pm 7.8$ & $256 \pm 20.2$ & $323 \pm 1.4$ & $375 \pm 1.4$ \\
\hline $4 \#$ & $269 \pm 4.9$ & $187 \pm 18$ & $65 \pm 5.7$ & $31 \pm 2.1$ & $139 \pm 5.7$ & $517 \pm 9.2 *$ & $227 \pm 21.2$ & $310 \pm 22.6$ \\
\hline $5 \#$ & $222 \pm 7.1$ & $164 \pm 16.3$ & $74 \pm 6.4$ & $44 \pm 0.7$ & $162 \pm 11.0$ & $320 \pm 25.5$ & $408 \pm 5.7$ & $638 \pm 59.4$ \\
\hline 7\# & $267 \pm 14.1$ & $196 \pm 17.7$ & $66 \pm 6.4$ & $52 \pm 4.6$ & $149 \pm 12.7$ & $331 \pm 32.5$ & $440 \pm 19.2$ & $500 \pm 17.7$ \\
\hline Blank & $182 \pm 12$ & $166 \pm 11.9$ & $53 \pm 4.9$ & $51 \pm 1.4$ & $181 \pm 4.4$ & $205 \pm 6$ & $321 \pm 11.3$ & $342 \pm 1.4$ \\
\hline DMSO & $305 \pm 10.6$ & $309 \pm 19.1$ & $62 \pm 2.8$ & $72 \pm 3.5$ & $196 \pm 11.1$ & $194 \pm 9.1$ & $340 \pm 26.9$ & $344 \pm 11.3$ \\
\hline
\end{tabular}

${ }^{*} \mathrm{MR} \geq 2$ compared to control. 

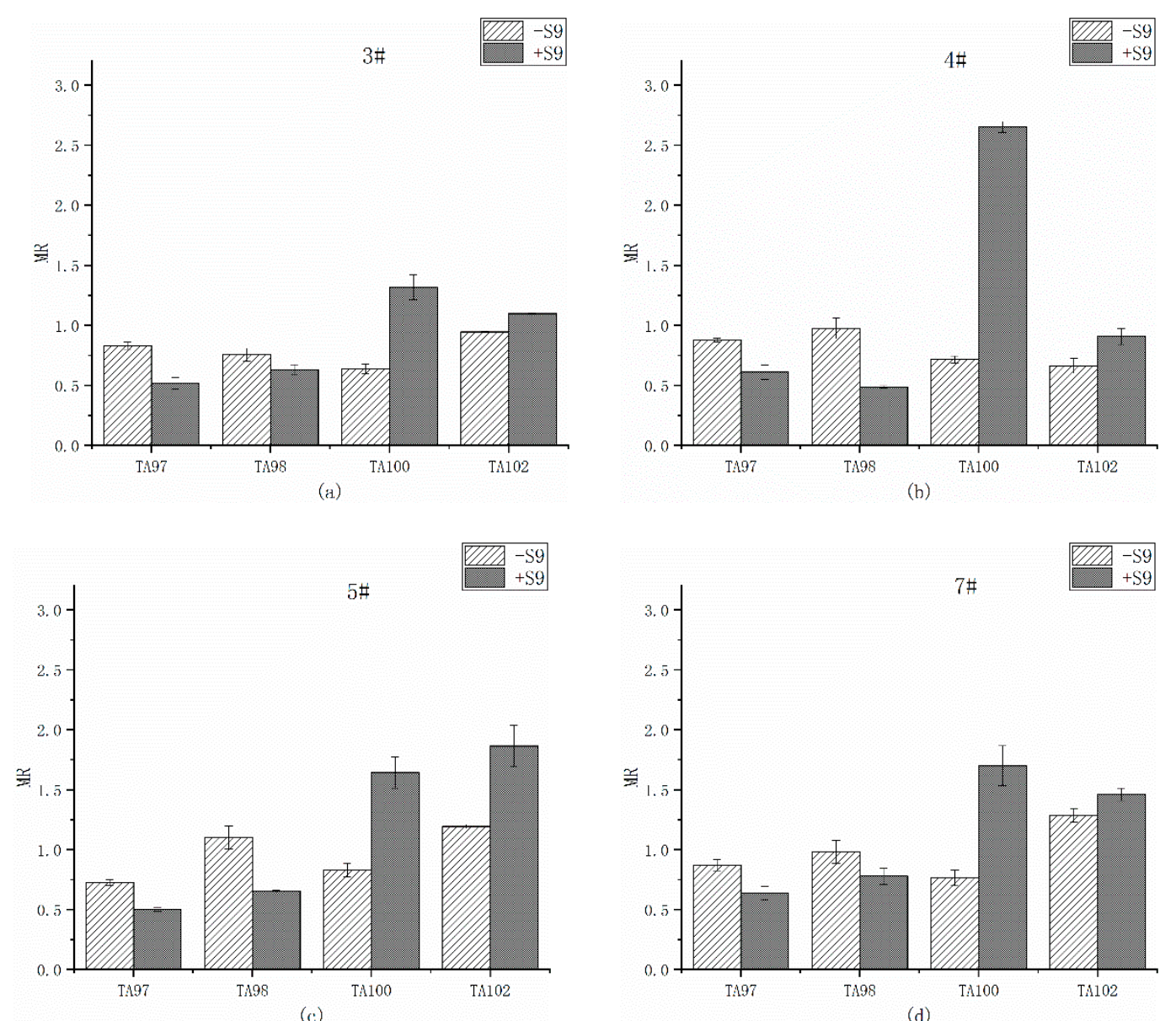

Figure 3. Mutagenesis of four strains by overlying water in the presence and absence of liver microsomal S9; (a) site 3\#; (b) site 4\#; (c) site 5\#; (d) site 7\#. The mutagenicity ratio (MR) is the average ratio from 3 independent experiments.

\section{Conclusions}

- Acute toxicity of overlying water from Shengtongbang by C. vulgaris tests showed nontoxic before and after remediation, but promoted the growth of $C$. vulgaris because of the excessive TN and TP, indicated that the restrictions on the TN and TP are still needed.

- The D. magna tests showed the toxicity of overlying water on site 3\# before remediation, and be declined to nontoxic after remediation. The results suggested the remediation effects were effective for D. magna.

- The mutagenicity of organic extracts from overlying water by Ames test at all sampling sites was positive before remediation. After remediation, the mutagenicity of most sites eliminated except of the TA98 strain from 3 of 4 sites. The addition of liver microsomal S9 induced the positive mutagenicity on site $4 \#$, implying that the metabolism of the microorganisms changed the mutagenicity of the organic extracts from overlying water. The remediation significantly improved the water quality, but the potential ecological risk still exists in Shengtongbang.

- The results of this study applied comprehensive toxicity tests to evaluate the remediation results in urban black-odor rivers, and provided biological assessing method for the remediation evaluation.

Author Contributions: Conceptualization, R.-R.X., L.-W.S., and Y.-M.Z.; data curation, W.-Q.W. and J.Z.; formal analysis, R.-R.X. and L.-W.S.; funding acquisition, L.-W.S. and Y.-M.Z.; investigation, L.-L.Z. and M.Z.; methodology, R.-R.X.; project administration, L.-W.S. and Y.-M.Z.; resources, Y.-M.Z.; supervision, L.-W.S.; validation, R.-R.X. and Z.-T.P.; visualization, Z.-T.P. and W.-Q.W.; writing-original draft preparation, R.-R.X.; writing-review and editing, L.-W.S. and Y.-M.Z. All authors have read and agreed to the published version of the manuscript. 
Funding: This research was funded by the Environmental Monitoring Project in the Jiangsu Province, grant number 1803, the Scientific Research Project of Treatment of Water Pollution in Taihu (Tenth Issue), grant number JSZC-G2016-198, and the National Key Research and Development Program-China, grant number 2018YFC1803100.

Acknowledgments: We are grateful to the Coordination with Changzhou University for the help of sampling and guidance from Jiangsu Provincial Environmental Monitoring Suzhong Sub-center on solid-phase extraction method.

Conflicts of Interest: The authors declare no conflict of interest.

\section{References}

1. Wang, X.; Wang, Y.G.; Sun, C.H.; Pan, T. Formation mechanism and assessment method for urban black and odorous water body: A review. Chin. J. Appl. Ecol. 2016, 27, 1331-1340.

2. Kerr, J.L.; Baldwin, D.S.; Whitworth, K.L. Options for managing hypoxic blackwater events in river systems: A review. J. Environ. Manag. 2013, 114, 139-147. [CrossRef] [PubMed]

3. Davenport, A.J.; Gurnell, A.M.; Armitage, P.D. Habitat survey and classification of urban rivers. River Res. Appl. 2004, 20, 687-704. [CrossRef]

4. Malmaeus, J.; Hakanson, L. Development of a lake eutrophication model. Ecol. Model. 2004, 171, 35-63. [CrossRef]

5. Sugiura, N.; Utsumi, M.; Wei, B.; Iwami, N.; Okano, K.; Kawauchi, Y.; Maekawa, T. Assessment for the complicated occurrence of nuisance odours from phytoplankton and environmental factors in a eutrophic lake. Lakes Reserv. Res. Manag. 2004, 9, 195-201. [CrossRef]

6. Shen, Q.; Zhu, L.; Cao, H.Y. Remote sensing monitoring and screening for urban black and odorous water body: A review. Chin. J. Appl. Ecol. 2017, 28, 3433-3439.

7. Chen, G.; White, P.A. The mutagenic hazards of aquatic sediments: A review. Mutat. Res. 2004, 567, 151-225. [CrossRef]

8. USEPA. Methods for Measuring the Acute Toxicity of Effluents and Receiving Waters to Freshwater and Marine Organisms; U.S. Environmental Protection Agency: Washington, DC, USA, 2002.

9. Fang, Y.X.; Ying, G.G.; Zhang, L.J.; Zhao, J.L.; Su, H.C.; Yang, B.; Liu, S. Use of TIE techniques to characterize industrial effluents in the Pearl River Delta region. Ecotoxicol. Environ. Saf. 2011, 76, 143-152. [CrossRef]

10. Ames, B.N.; Mccann, J.; Yamasaki, E. Methods for detecting carcinogens and mutagens with the Salmonella/mammalian-microsome mutagenicity test. Mutat. Res. 1975, 31, 347-363. [CrossRef]

11. Maron, D.M.; Ames, B.N. Revised methods for the Salmonella mutagenicity test. Mutat Res. 1983, 113, 173-215. [CrossRef]

12. Park, J.H.; Lee, B.J.; Lee, S.K.; Kim, K.; Lee, K.H.; Che, J.H.; Kang, K.S.; Lee, Y.S. Genotoxicity of drinking water from three Korean cities. Mutat. Res. 2000, 466, 173-178. [CrossRef]

13. Kutlu, M.; Aydoğan, G.; Susuz, F.; Özata, A. The Salmonella mutagenicity of water and sediments from the Porsuk River in Turkey. Environ. Toxicol. Phar. 2004, 17, 111-116. [CrossRef] [PubMed]

14. Environmental Quality Standards for Surface Water, GB3838-2002. General Administration of Quality Supervision, Inspection and Quarantine of the People's Republic of China. Available online: http://www.mee. gov.cn/ywgz/fgbz/bz/bzwb/shjbh/shjzlbz/200206/W020061027509896672057.pdf (accessed on 1 June 2002).

15. The State Environmental Protection Administration. Water and Wastewater Monitoring and Analysis Method, 4th ed.; China Environmental Science Press: Beijing, China, 2002.

16. Eaton, A.D.; Clesceri, L.S.; Greenberg, A.E.; Franson, M.A.H. Standard methods for the examination of water and wastewater. Am. J. Public Health Nations Health 1995, 56, 387-388.

17. Chemicals-Alga Growth Inhibition Test, GB/T 21805-2008. General Administration of Quality Supervision, Inspection and Quarantine, People's Republic of China; Standardization Administration of China. Available online: https://www.spc.org.cn/online/GB\%252FT\%252021805-2008/ (accessed on 12 May 2008).

18. Tonkes, M.; De Graaf, P.J.; Graansma, J. Assessment of complex industrial effluents in the Netherlands using a whole effluent toxicity (or WET) approach. Water Sci. Technol. 1999, 39, 55-61. [CrossRef]

19. Persoone, G.; Marsalek, B.; Blinova, I.; Törökne, A.; Zarina, D.; Manusadzianas, L.; Nalecz-Jawecki, G.; Tofan, L.; Stepanova, N.; Tothova, L. A practical and user-friendly toxicity classification system with microbiotests for natural waters and wastewaters. Environ. Toxicol. Int. J. 2003, 18, 395-402. [CrossRef] 
20. Method for Acute Toxicity Test of Daphnia Magna Straus, GB/T 16125-2012. Ministry of Health, People's Republic of China, Standardization Administration of China. Available online: http://c.gb688.cn/bzgk/gb/ showGb?type =online\&hcno=E86B0B717CF7AF44C15AA64118D14E85 (accessed on 20 September 2012).

21. Ra, J.S.; Lee, B.C.; Chang, N.I.; Kim, S.D. Comparative whole effluent toxicity assessment of wastewater treatment plant effluents using Daphnia magna. Bull. Environ. Contam. Toxicol. 2008, 80, 196-200. [CrossRef]

22. Safety and Technical Standards for Cosmetics. China Food and Drug Administration. Available online: http: //samr.cfda.gov.cn/directory/web/WS01/images/MjAxNcTqtdoyNji6xbmruOa4vbz+LnBkZg==.pdf (accessed on 23 December 2015).

23. Saskia, R.; Werner, K.; Christiane, Z. Short-term exposure with high concentrations of pristine microplastic particles leads to immobilisation of Daphnia magna. Chemosphere 2016, 153, 91-99.

24. Kluwe, W.M.; McConnell, E.E.; Huff, J.E.; Haseman, J.K.; Douglas, J.F.; Hartwell, W.V. Carcinogenicity testing of phthalate esters and related compounds by the National Toxicology Program and the National Cancer Institute. Environ. Health Perspect. 1982, 45, 129-133. [CrossRef]

25. Alabi, O.A.; Sorungbe, A.A.; Adeoluwa, Y.M. In vitro mutagenicity and genotoxicity of raw and simulated leachates from plastic waste dumpsite. Toxicol. Mechan. Method. 2019, 29, 1-23. [CrossRef]

26. Li, G.L.; Lang, Y.H.; Gao, M.S.; Wei, Y.; Peng, P.; Wang, X.M. Carcinogenic and mutagenic potencies for different PAHs sources in coastal sediments of Shandong Peninsula. Marine Pollut. Bull. 2014, 84, 418-423. [CrossRef]

27. Gu, Y.G.; Lin, Q.; Lu, T.T.; Ke, C.L.; Sun, R.X.; Du, F.Y. Levels, composition profiles and sources of polycyclic aromatic hydrocarbons in surface sediments from Nan'ao Island, a representative mariculture base in South China. Marine Pollut. Bull. 2013, 75, 310-316. [CrossRef] [PubMed]

28. Dong, C.D.; Chen, C.F.; Chen, C.W. Vertical profile, sources, and equivalent toxicity of polycyclic aromatic hydrocarbons in sediment cores from the river mouths of Kaohsiung Harbor, Taiwan. Marine Pollut. Bull. 2014, 85, 665-671. [CrossRef] [PubMed]

29. Vanhulle, S.; Trovaslet, M.; Enaud, E.; Lucas, M.; Taghavi, S.; Van, d.L.D.; Van, A.B.; Foret, M.; Onderwater, R.C.; Wesenberg, D. Decolorization, cytotoxicity, and genotoxicity reduction during a combined ozonation/fungal treatment of dye-contaminated wastewater. Environ. Sci. Technol. 2008, 42, 584-589. [CrossRef]

30. Bryer, P.J.; Elliott, J.N.; Willingham, E.J. The effects of coal tar based pavement sealer on amphibian development and metamorphosis. Ecotoxicology 2006, 15, 241-247. [CrossRef] [PubMed]

31. Wetmore, B.A.; Struve, M.F.; Gao, P.; Sharma, S.; Allison, N.; Roberts, K.C.; Letinski, D.J.; Nicolich, M.J.; Bird, M.G.; Dorman, D.C. Genotoxicity of intermittent co-exposure to benzene and toluene in male CD-1 mice. Chem. Biol. Interact. 2008, 173, 166-178. [CrossRef]

32. Hladik, M.L.; Smalling, K.L.; Kuivila, K.M. A Multi-residue Method for the Analysis of Pesticides and Pesticide Degradates in Water Using HLB Solid-phase Extraction and Gas Chromatography-Ion Trap Mass Spectrometry. Bull. Environ. Contam. Toxicol. 2008, 80, 139-144. [CrossRef]

33. Hughes, T.J. Genotoxicity of industrial wastes and effluents. Mutat. Res. 1998, 410, 237.

(C) 2020 by the authors. Licensee MDPI, Basel, Switzerland. This article is an open access article distributed under the terms and conditions of the Creative Commons Attribution (CC BY) license (http://creativecommons.org/licenses/by/4.0/). 